Canadian

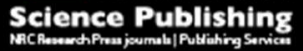

Botany

Botanique

\title{
Mechanisms by which basal branches suppress axillary bud outgrowth in pea (Pisum sativum)
}

\begin{tabular}{|r|l|}
\hline Journal: & Botany \\
\hline Manuscript ID & cjb-2017-0198.R1 \\
\hline Danuscript Type: & Article \\
\hline $\begin{array}{r}\text { Complete List of Authors: } \\
\text { Is the invited manuscript for } \\
\text { consideration in a Special } \\
\text { Issue? : }\end{array}$ & $\begin{array}{l}\text { Thomas, Roderick; AgResearch Ltd Science Group Forage Improvement } \\
\text { Improvement }\end{array}$ \\
\hline Keyword: & $\begin{array}{l}\text { auxin, axillary bud outgrowth, basal branches, correlative inhibition, stem } \\
\text { girdling }\end{array}$ \\
\hline &
\end{tabular}

SCHOLARONE $^{\mathrm{m}}$

Manuscripts 
Mechanisms by which basal branches suppress axillary bud outgrowth in pea (Pisum sativum)

R. G. Thomas ${ }^{A}$ and M. J. M. Hay ${ }^{A B}$

${ }^{A}$ Forage Improvement, AgResearch Grasslands, Private Bag 11008, Palmerston North, New Zealand.

${ }^{\mathrm{B}}$ Corresponding author. Email: mike.hay@agresearch.co.nz

Ph. +6463518115

Fax +6463518138

Running title: Suppression of bud outgrowth by basal branches 


\begin{abstract}
This study examined whether the strong inhibitory influences of basal branches on axillary bud outgrowth seen in Trifolium repens similarly occur in Pisum sativum. Mechanisms by which basal branches in P. sativum suppress bud outgrowth were assessed using treatment combinations of main stem decapitation and excision, girdling and/or disbudding of basal branches. The combination of decapitation with basal branch excision provided a new avenue for investigation of correlative suppression of bud outgrowth. Results revealed a dual suppressive action of basal branch buds: girdling of basal branches confirmed they act via export of an inhibitory influence but also demonstrated, for the first time in P. sativum, their role as competitive sinks for a bud outgrowth stimulus. Although all axillary buds on the main stem had similar intrinsic potential for outgrowth, sensitivity to these suppressive influences varied with position on the stem. This suppressive influence of basal branches was, like apical dominance, a major influence on the regulation of bud outgrowth. The finding in $P$. sativum that basal branches suppress bud outgrowth via their action as competitive sinks for an outgrowth stimulus as they do in nodally-rooting clonal herbs suggests further investigation of this process is warranted.
\end{abstract}

Key words: auxin, axillary bud outgrowth, basal branches, branch excision, correlative inhibition, decapitation, stem girdling 


\section{Introduction}

During growth of an angiosperm shoot, it is normal for one or two buds to form in the axil of each leaf. Each of these axillary buds has the innate capacity to grow out into an elongating branch (Phillips 1975) but many fail to do so. This may be because buds have transitioned to the reproductive state, are non-viable or quiescent as a result of correlative inhibition imposed by other parts of the plant or because of unfavourable environmental conditions (Newton et al. 1992). There are advantages in maintaining a pool of quiescent buds as these permit efficient plant development by preventing overlap of the resource-acquiring zones of organs, such as leaves or roots, and the accumulation of a bank of buds from which regeneration may occur after any severe damage by biotic or abiotic influences (Harper 1977).

The distribution of quiescent versus actively growing buds along a shoot is not random but tends to reveal a distinct pattern of zonation. This is particularly apparent in annual species, such as Pisum sativum (Hussain and Linck 1966; King and van Staden 1988), and in response to nodal rooting in prostrate clonal herbs (Thomas et al. 2014). In both cases an initial phase of bud outgrowth to form a highly branched basal zone on the shoot is followed by a phase in which bud outgrowth is suppressed to form an 'inhibition zone' (Weberling 1989). In species with determinate flowering, a phase of renewed bud outgrowth at the shoot tip then accompanies the transition to the reproductive phase and leads to the formation of a terminal ‘enrichment zone' (Weberling 1989).

A key question arising from these observations relates to the failure of buds in the inhibition zone to grow out into elongating branches. Horticulturists have known since before the time of Theophrastus, in the fourth century B.C., that the outgrowth of branches from such quiescent buds can be stimulated by 'pinching out' the apical buds above them. This implies that, in an intact plant, outgrowth of axillary buds into elongating branches is suppressed by the presence of an apical bud above them on the main stem. Because this 'apical dominance' over the outgrowth of buds lower down the main stem occurs throughout a very wide range of angiosperm taxa, it is widely accepted as a primary cause of bud outgrowth suppression and has come to be a major focus of research into the regulation of branching (e.g. (and references within) Phillips 1975; Hillman et al. 1977; Cline 1991; Tamas 1995; Napoli et al. 1999; Dun et al. 2006; Ferguson and Beveridge 2009; Müller and Leyser 2011). Such research has been concentrated largely on a few annuals with determinate flowering, such as Arabidopsis, Pisum sativum and Petunia, with the emphasis of more recent work on the part 
played by the action of auxin via its interactions with other phytohormones (Beveridge 2006; Simons et al. 2007; Ongaro and Leyser 2008; Ferguson and Beveridge 2009; Shimizu-Sato et al. 2009; Leyser 2009; Crawford et al. 2010; Shinohara et al. 2013; Brewer et al. 2013; Bennett et al. 2016).

Early work using simple two-branched systems in pea and bean where decapitation of the main stem above the second node induced basal nodes to branch clearly showed that the growth of one branch could repress the growth of the other (Snow 1931). It is now also clear that basal branches can play an important regulatory role in the regulation of axillary bud outgrowth along the main stem. This is particularly apparent in prostrate nodally rooted clonal herbs with indeterminate flowering (Thomas and Hay 2004, 2008a, b, 2011, 2015b; Thomas et al. 2014). In genera as taxonomically diverse as Glechoma (Lamiaceae), Vinca (Apocynaceae), Acaena (Rosaceae), Calystegia (Convolvulaceae), Trifolium (Fabaceae) and the monocotyledon Tradescantia (Commelinaceae), quiescent buds in the inhibition zone can be stimulated to grow out strongly into elongating branches by the excision of the branches proximal to them in the basal zone. In these species the suppressive influence of basal branches can be as profound as, or greater than, that of the apical bud (Thomas et al. 2003b; Thomas and Hay 2004, 2008b). In Trifolium repens, for example, outgrowth of quiescent buds in response to excision of the apical bud is very weak (Thomas et al. 2003b; Thomas and Hay 2014, 2015b). Using this species as an exemplar for this group, it has been shown that buds on the basal branches act largely as competitive sinks for a root-produced promoter (Thomas et al. 2003a) that is possibly a cytokinin (Thomas and Hay 2015a).

The suppressive effect of basal branches is not confined to nodally rooting clonal herbs. Axillary bud outgrowth in the inhibition zone can similarly be stimulated by excision of branches in the basal zone in the monopodial annuals Pisum sativum (Thomas and Hay 2008a; Ferguson and Beveridge 2009) and Petunia (Thomas and Hay, unpublished). In contrast to the situation in $T$. repens, however, it has been proposed that in $P$. sativum the basal branches act via the export of an inhibitory compound (Dun et al. 2009).

To assess further the mechanisms by which basal branches suppress, experiments using $P$. sativum were designed to distinguish between two fundamentally different possibilities; namely, that suppression must result either from export of an inhibitory compound from the basal branches into the rest of the plant or as a result of import of a stimulatory compound into the basal branches in competition with the main stem. In addition, because the inhibitory 
role of the main stem apical bud in $P$. sativum has been well established while in the closely related $T$. repens a more important role of basal branches was found, the present study set out to assess the relative importance of bud suppression by basal branches in P. sativum compared with that imposed by apical dominance.

For the purposes of this investigation, a cultivar of $P$. sativum ( $c v$. Greenfeast) was chosen in which the two basalmost branches grow to become equivalent in size and equal in growth rate to the main stem, but in which growth of all other buds is suppressed to varying degrees in intact plants. This cultivar provides a sensitized system for study of the relative contributions of bud inhibition by basal branches versus the main stem apical bud. Treatments involving total basal branch excision (debranching), excision of all buds on basal branches (disbudding) and /or girdling of the two basalmost branches were applied to test the following hypotheses:

1. that basal branches suppress distal axillary bud outgrowth

2. that the suppressive influence of basal branches arises from their active buds

3. that the suppressive influence of basal branches acts via a mechanism involving export of an inhibitory signal

4. that the basal branches suppress distal bud outgrowth by acting as competitive sinks for a stimulating compound

5. that the suppressive influence of basal branches is mediated by a signal involving auxin action and,

6. that the suppressive role of the basal branches is less than that of the main stem apical bud.

Pivotal treatments involved the application of a hot wax girdle to the base of each of the two basalmost branches. Such treatment has been shown to kill all live cells in the girdled region (Thomas and Hay 2011), thereby preventing the transport of compounds (signals), such as auxin (Ferguson and Beveridge 2009), into and out of the branches via the phloem and other symplastic tissues, while allowing continued import of compounds in the transpiration stream via the xylem. A stimulatory effect of girdling, by blocking export while allowing xylem import, would support Hypothesis 3; a lack of response would disprove it and, instead, support Hypothesis 4. 
Because variation from node to node in the vigour of bud outgrowth along the main stem might in part be attributed to variation in bud sensitivity to hormonal signals (King and van Staden 1988; Stafstrom 1995), tests were made of an additional hypothesis:

7. that all buds present along the main stem have similar innate outgrowth potentials.

To overcome any possible overshadowing of the suppressive influence of basal branches by a stronger inhibitory influence from the main stem apical bud, treatments were applied to basal branches on both intact plants and on those from which the apical bud had been excised. Such a treatment combination of basal branch excision and decapitation has not previously been reported.

\section{Materials and methods}

\section{Plant materials}

Plants were grown from seeds of a late flowering dwarf cultivar of Pisum sativum L. cv. 'Greenfeast', supplied by McGregor's Horticulture Ltd, Auckland, New Zealand, in which one large branch is produced at each of the two basalmost nodes (nodes 1 and 2) distal to the cotyledons on the main stem.

\section{Hormone materials}

Hydrous lanolin paste, used in control treatments, was produced by adding water to melted anhydrous lanolin in the ratio 3:2 (lanolin:water) by weight and then vigorously stirring the mixture. For the NAA and NPA treatments, 1-naphthaleneacetic acid (NAA) or N-1naphthylphthalamic acid (NPA), respectively, was dissolved in ethanol, then added to the lanolin paste and thoroughly mixed in so as to give a concentration of $10 \mathrm{mg}$ active ingredient $\mathrm{g}^{-1}$ lanolin. All lanolin-based treatments were applied twice weekly.

\section{Culture of experimental plants}

Seeds, pre-soaked in running water overnight, were planted, one per 1.81 container, into commercially obtained potting mix (Thomas et al. 2002). Plants were grown in a heated greenhouse in Palmerston North, New Zealand in natural daylengths at average daily 
maximum/minimum temperatures of $25 / 12{ }^{\circ} \mathrm{C}$. The one or two accessory buds that formed alongside the main axillary buds at nodes 1 and 2 were excised from all plants.

\section{Experimental methods}

Experiments 1 and 2 were undertaken to test Hypotheses 1 to 6, stated in the Introduction, regarding the relative roles of the apical bud and basal branches in the regulation of axillary bud outgrowth into branches.

In both experiments, plants were grown until the $12^{\text {th }}$ node $(\mathrm{N} 12)$ on their main stem was newly emerged from the apical bud. Plants were then divided into two groups in which apical buds were either retained $(+\mathrm{AB})$ or excised $(-\mathrm{AB})$ by cutting through the midpoint of the internode immediately distal to N12. Microscopic dissection and examination of the excised apical buds showed that these plants had already undergone a transition to flowering by this time: axils of leaf primordia within the apical buds from node 20 upwards all contained flower primordia at early stages of development. In each group $( \pm A B)$, five treatments were applied to the basal branches at nodes 1 and 2 on the main stem (Figs. 1 and 2). Three of these were common to both experiments:

(C) untreated control

(X) total excision of the two basal branches close to their point of attachment to the primary stem, and

(G) basal branches girdled at the midpoint of their second oldest internode. Girdling was effected by pouring molten candle wax, heated to $110^{\circ} \mathrm{C}$, into a Blu-tack (Bostik) 'cup' surrounding the internode as described by Ferguson and Beveridge (2009).

In Experiment 1, seeds were sown 28 September 2010 and treatments applied to eight replicates of ten plants (five $(+A B)$ and five $(-A B)$ ) at age $37 \mathrm{~d}$ on 4 November. The five treatments to the two basal branches (see Fig. 1) included the following two in addition to (C), (X) and (G):

(D) disbudding by excision of all axillary buds together with the apical bud, and $(D+G)$ disbudding as in $(D)$, with the addition of girdling as in $(G)$.

In Experiment 2, seeds were sown 25 March 2010 and treatments applied, as for Experiment 1, to the two basal branches on six replicates of ten plants (five $(+A B)$ and five $(-A B))$ at age $32 \mathrm{~d}$ on 26 April (see Fig. 2). Treatment $\mathrm{G}$ was as for Experiment 1 but treatment $\mathrm{C}$ was modified to act as a control for treatment NPA (see below) by applying hydrous lanolin paste 
to the second internode of each of the two basal branches, and in treatment $\mathrm{X}$ hydrous lanolin paste was applied to the stubs remaining after branch excision, thereby enabling it to act as a control for treatment NAA (see below). The two additional treatments were:

(NPA) application of lanolin paste containing NPA to the midpoint of the second oldest internode on each intact basal branch, and

(NAA) basal branches excised, as in (X), but lanolin paste containing NAA was applied to the stubs remaining after basal branch excision.

In an additional group of six plants (treatment $\mathrm{Z}$ ) apical buds were retained $(+\mathrm{AB})$ but all buds and branches were excised from nodes 1 to 11 on the main stem.

In both Experiments 1 and 2, total lengths and stem lengths of all buds on the main stem distal to nodes 1 and 2 were measured at the time treatments were applied and again after 1 , 2, 4 and $9 \mathrm{~d}$. Intact plants $(+\mathrm{AB})$ were grown on for a further $9 \mathrm{~d}$ to determine the position of the lowest flowering node.

Experiments 3 and 4 were designed to test Hypothesis 7. In Experiment 3, eighteen plants were grown for $38 \mathrm{~d}$ from seeds sown on 12 August 2011 until node 12 (N12) had just emerged from its parent apical bud on the main stem (Fig. 3). Six plants were left intact as controls (treatment (i)), six had their main stems decapitated by excision of their apical buds midway along the newly emerged internode distal to N12 (treatment (ii)), and six were similarly decapitated immediately distal to node 9 (N9) (treatment (iii)). All buds and branches along the main stem were retained, those at N9 being three phyllochrons older than those recently emerged from the apical bud at N12.

Experiment 4 was set up to test whether, irrespective of their nodal positions on the main stem, all actively growing axillary buds respond similarly to decapitation immediately distal to them at the time they are newly emerged from the main stem's apical bud. Sowing dates were staggered to produce three groups of 18 plants $(\mathbf{a}, \mathbf{b}$ and $\mathbf{c})$ of different ages at the time simultaneous treatments were applied (Fig. 4). Seed was sown on 12 August for group a (as for Experiment 3), 22 August for group $\mathbf{b}$ and 6 September for group $\mathbf{c}$. Six plants of each group were subjected to one of three treatments. Those receiving treatments (i) and (ii) retained all their axillary buds, and branches developed from them, up to the time of decapitation. Those in treatment (i) continued to retain these, but in treatment (ii) all buds at nodes below the distalmost two were excised immediately after decapitation of the main 
stem. In treatment (iii) each bud except the two uppermost was excised at the time it emerged from its parent apical bud. In group a, axillary buds were excised from nodes 1-10, leaving those at N11 and N12 to respond to decapitation; in b, buds were excised from nodes 1-7 leaving those at N8 and N9 and, in c, buds were excised from nodes 1-3 leaving buds at N4 and N5 (Fig. 4).

All plants were decapitated during the week of 20-25 September when plants in groups a, $\mathbf{b}$ and $\mathbf{c}$ were aged roughly 38,30 and $19 \mathrm{~d}$ respectively.

For both Experiments 3 and 4 overall lengths of buds and bud stem lengths were measured 7 $\mathrm{d}$ after treatments were applied.

\section{Data analysis}

In each of Figures 1 to 6, data represent the means of only those buds that were present; budless nodes were excluded from calculations. For each of the assessed characteristics, across all experiments, the treatment means and standard errors of the means were obtained using Oneway ANOVA in the GenStat (18 ${ }^{\text {th }}$ Edition) statistical package. (VSN International, 2015).

The simple regressions reported in Fig. 5 were also analysed using the GenStat ( $18^{\text {th }}$ Edition) statistical package.

\section{Results}

\section{Basal branches suppress distal axillary bud outgrowth}

Results of Experiments 1 and 2 show Hypothesis 1 to be correct: basal branches in $c v$. Greenfeast suppress axillary bud outgrowth in a similar way to that shown to occur in the rms2.1 mutant of $c v$. Torsdag reported by Ferguson and Beveridge (2009).

In non-decapitated plants ( $+\mathrm{AB})$, excision of basal branches at nodes 1 and 2 (treatment $\mathrm{X}$ ) in Experiments 1 and 2 (Figs. 1 and 2, Group A) stimulated bud outgrowth relative to that in controls (C) at all nodes along the main stem. Comparable excision treatments in decapitated plants $(-\mathrm{AB})$ induced a similar, but far greater, stimulation to that in non-decapitated plants (Figs. 1 and 2, Group B).

\section{The buds on basal branches are the source of the suppressive influence}


Disbudding of basal branches in Experiment 1 (treatment D) had the same stimulatory effect on axillary bud outgrowth as did branch excision, both with $(-\mathrm{AB})$ and without $(+\mathrm{AB})$ decapitation of the main stem (Fig. 1 (D) vs. (X)). The stimulatory effect in the apical zone distal to node 12 was increased by additionally disbudding and debranching up to node 12 in Experiment 2 (Table 1), ((Z) vs. (X)). The results obtained thus support Hypothesis 2, that it is the buds on the basal branches that are the source of this suppressive influence.

\section{Girdling basal branches demonstrates that two suppressive mechanisms operate}

\section{Effect on basal branch growth}

Extension growth rates of non-girdled basal branches at nodes 1 and 2 in non-decapitated control plants over the first 9 days in Experiments 1 and 2 were similar to those of the main stem, although they averaged 10\% less: $16.45 \mathrm{vs} .18 .25 \mathrm{~mm} . \mathrm{d}^{-1}$ respectively (see supplementary Table S1). Girdling of these branches did not reduce their growth rates, and thus did not impede the supply of necessary growth factors into them from the root system via the apoplast.

\section{Effect on axillary bud outgrowth}

Girdling of basal branches in Experiments 1 and 2, to restrict transport into and out of them via the symplast while allowing transport into them via the xylem, stimulated axillary bud outgrowth along the main stem in both non-decapitated $(+A B)$ and decapitated $(-A B)$ plants. This was particularly marked in decapitated plants and was apparent after 2 days in Experiment 2 (Table 2). To overcome the problem that initial bud sizes were very variable and the possibility, therefore, that differences between the means reflect this variability, the relationship between initial bud size and that measured after 4 days is shown in Figure 5. Clearly, outgrowth of the bud at node 3 in girdled plants had been stimulated similarly to that in both (X) and (NAA) treatments during that time. This rapid initial response to girdling of basal branches was not maintained in non-decapitated plants $(+A B)$. There was little or no effect on bud stem length increase from day 5 to day 9 (Experiments 1 and 2, Figs. 1 and 2), in contrast to the stimulation induced by total basal branch excision (X) or disbudding (D). Clearly noticeable was the lack of stimulation in buds distal to node 4, particularly in the apical zone distal to N12. This failure of girdling to overcome the suppressive influence of basal branches in the presence of the main stem apical bud (Figs. 1 and 2, Group A (C) vs. (G)) supports Hypothesis 4 that the basal branches act as competitive sinks for the supply of a root-derived bud outgrowth stimulant via the xylem. There was no indication that the 
presence of a girdle increased the level of bud outgrowth stimulant in the main shoot by blocking its transport into the basal branches via the phloem. In intact plants $(+A B)$ shortage of bud outgrowth stimulant resulting from competition between the main stem's apical bud and the basal branches is the primary factor limiting axillary bud outgrowth. This stimulant moves into the basal branches via the xylem.

In contrast to the response of intact plants, in decapitated plants $(-\mathrm{AB})$ the initial, short-lived stimulation of axillary bud outgrowth in response to girdling continued throughout the full nine-day period of the experiments (Figs. 1 and 2, Group B (G) vs (C)). In both Experiment 1 and 2 the stimulatory response to girdling $(\mathrm{G})$, was little different from the response to total excision of basal branches. Because evidence from intact plants $(+A B)$ suggests that a bud outgrowth stimulant was transported into the basal branches predominantly via the xylem rather than the phloem, the marked stimulatory response to girdling in decapitated plants (AB) strongly supports Hypothesis 3, that basal branches act by the export of an inhibitory signal via the symplast that is prevented by the application of a girdle. The resulting stimulation of axillary bud outgrowth by the prevention of export of the inhibitory signal from the basal branches was comparable, in the lowermost and uppermost zones of the main stem, to that induced by total basal branch excision (X) and disbudding (D).The response in the middle region from node 6 to 10 was considerably weaker, however, especially in Experiment 1 (Fig. 1, (G) vs. (X) and (D)) and with regard to bud stem length increases from day 5 to 9 in both experiments.

\section{The effect of girdling disbudded basal branches}

In non-decapitated plants in Experiment 1 (Fig. 1 (+AB)), girdling of disbudded basal branches $(D+G)$ had no apparent effect on axillary bud outgrowth at any position on the main stem; bud outgrowth on these plants was closely similar to that on plants in which basal branches were disbudded alone (D) or completely excised (X). Outgrowth in response to all three of these treatments was better than in response to girdling alone, (Fig. 1, (G)). Importantly, however, comparison of the results of treatments $(G)$ and $(D+G)$, in which export from the basal branches via the symplast would have been equally blocked by the girdles, shows a stimulatory effect of disbudding. In the absence of export of a suppressive signal this stimulatory effect must have occurred, therefore, as a result of the action of buds as competitive sinks for compounds promoting the outgrowth of axillary buds along the main stem (Hypothesis 4). 
In contrast, comparison of the response to treatments $(\mathrm{G})$ and $(\mathrm{D}+\mathrm{G})$ in decapitated plants (Fig. $1(-\mathrm{AB})$ ), in which export via the symplast would have been similarly blocked, shows little or no response to disbudding. Thus, in the absence of the main stem apical bud acting in competition with the basal branches, their competitive effect is reduced and they must act, as proposed in Hypothesis 3, via the export of an inhibitory signal.

\section{Auxin export from basal branches does not drive their suppressive effect}

Treatment of basal branches with NPA to depress possible auxin flow out into the main stem had no effect on axillary bud outgrowth on either non-decapitated (+AB) or decapitated (AB) plants in Experiment 2 (Fig. 2 groups A and B, (C) vs. (NPA) and Table 1). NPA did not affect the elongation rate of the main stem or of the branches to which it was applied, either (see Supplementary Table S1). Similarly, substitution of applied NAA for basal branches (Fig. 2 groups A and B, (X) vs. (NAA) and Table 1) had no effect on main stem elongation or axillary bud outgrowth. These results do not support Hypothesis 5, that the suppressive effect of basal branches is caused by their export of auxin into the main stem.

\section{The suppressive effect of basal branches is as great as that of the apical bud}

In Experiments 1 and 2 decapitation distal to node 12 stimulated axillary bud outgrowth at nodes 12 and 11 in plants that retained their basal branches but had little stimulatory effect on more proximal buds, particularly with regard to bud stem elongation during days 4 to 9 (Figs. 1 and $2( \pm \mathrm{AB})$, treatment $\mathrm{C})$.

Comparison of the effects of basal branch excision (X) in non-decapitated plants (Figs 1 and $2(+\mathrm{AB})$, treatment $\mathrm{C} v s \mathrm{X})$ with those of decapitation on plants retaining their basal branches (Figs 1 and $2( \pm \mathrm{AB})$ treatment $C$ ) shows the stimulation of axillary bud outgrowth along the main stem at all nodes except 11 and 12 to have been greater in response to basal branch excision. Hypothesis 6, that the suppressive role of basal branches is less than that of the main stem apical bud, is therefore incorrect.

The strongest stimulation of axillary bud outgrowth in both experiments occurred in response to the combination of basal branch excision and decapitation (Figs. 1 and 2 (-AB), treatment $\mathrm{X})$. The effects of the two treatments were additive.

\section{All buds regardless of position have similar potential for outgrowth}

\section{Differential responses to decapitation}


Outgrowth vigour of a bud in response to decapitation or excision of basal branches varied with position on the main stem. This is seen most clearly in plants that were both decapitated above node 12 and had their branches excised at nodes 1 and 2 in Experiments 1 and 2 (Figs. 1 and 2 Group B (-AB) treatment X). Progressively, upwards along the main stem, there was a decline in bud outgrowth vigour from node 3 to node 5 that was followed by a zone of weakest outgrowth at nodes 6 to 8 and then a gradual increase in outgrowth to a maximum at node 12 .

In Experiments 1 and 2, axillary buds in the upper zone at node 11 and above responded to decapitation differently from those formed earlier lower on the main stem. Decapitation of otherwise intact plants immediately distal to node 12 led to the outgrowth of buds at nodes 11 and 12 but not of the older buds proximal to them (Figs. 1 and 2). Testing the possibility that stimulated activity of these outgrowing buds in some way prevented the outgrowth of those proximal to them, Experiment 3 showed that those at node 9 failed to grow out in response to decapitation immediately distal to them (Fig. 3). Because all tissues below node 9 were similar in each case, the failure of buds at node 9 to grow out might therefore have been attributable to their having a lower outgrowth potential than those at node 12 .

Unlike in Experiment 3, in which the buds at nodes 12 and 9 were of differing postemergence ages, with the latter emerging from its parent apical bud three phyllochrons earlier than that at node 12, Experiment 4 tested the response of buds at nodes 12, 9 and 5 when each was just newly emerged from the main stem apical bud (Fig. 4 (i), groups a, b and c). In this case neither the bud at node 9 nor that at node 5 responded to excision of the apical tissues distal to it, whereas outgrowth of that at node 12 was again strongly stimulated. The differences between bud outgrowth responses at nodes 12 and 9 thus related to their positions on the main stem rather than their developmental ages.

\section{Responses to excision of all proximal branches and/or buds}

In Experiment 4 (Fig. 4) all buds and branches proximal to two distal test buds of similar developmental age at nodes 12 and 11 (group a), 9 and 8 (group b) or 5 and 4 (group c) were excised either at the time of decapitation of the main stem immediately distal to the test buds (treatment (ii)) or sequentially from each node throughout the early growth of the plants as soon as they emerged from the main stem apical bud (treatment (iii)). At the time of decapitation of plants that had remained intact (late disbud), buds at nodes 11 and 12 were approximately twice as large as those at nodes 4 and 5 and those at nodes 8 and 9 were 
intermediate in size (Fig. 6a, $\mathbf{c}$ and $\mathbf{b}$ respectively). In each case disbudding and/or debranching of the proximal nodes stimulated outgrowth of the two remaining test buds strongly and similarly, regardless of their location on the stem. In the absence of proximal axillary buds all test buds thus possessed a similar intrinsic ability to grow out into branches as proposed by Hypothesis 7, but those at nodes 4 to 9 were sensitive to the suppressive influence of proximal buds and/or branches whereas those at nodes 11 and 12 were not. Bud outgrowth was greater following continual sequential removal of proximal buds (treatment (iii)) than when the latter were allowed to develop further before their excision at the time of decapitation (Fig. 4, treatment (ii)).

Continual bud excision had no effect on the rate of leaf initiation at the main stem's apical meristem (SAM) (Fig. 6 'cont..disbud' cf. 'late disbud'): the combined number of emerged nodes and those contained within the main stem apical bud was the same in plants that had retained all their proximal axillary buds up to the time of decapitation (late disbud) as in those that had been continually disbudded from an early age in each of the three groups (a, $\mathbf{b}$ and c). However, continual disbudding did result in axillary bud initiation two to three nodes closer to the SAM in the oldest plants (a) and one to two nodes closer in the younger plants (b and c). Following their initiation, rates of axillary bud growth from node to node within the main stem apical bud, as assessed by the rate of formation of leaf primordia upon them, were closely similar to those on plants that had retained their proximal main stem buds throughout. As a consequence, the earlier initiation of axillary buds in the plants that had been continually disbudded led to the test buds being two to three times larger than those in intact control plants (late disbud) at the time of their emergence from the main stem apical bud.

\section{Discussion}

The main aim of the present study was to assess further the mechanisms suppressing axillary bud outgrowth along the main stem of Pisum sativum. Experimental results showed the action of two mechanisms: axillary bud outgrowth is suppressed by inhibitory influences both from the main stem's apical bud (apical dominance) and from the basal branches. This study emphasised the role of basal branches as their role, although previously recognised (Snow 1931; Ongaro et al. 2008; Dun et al. 2009; Ferguson and Beveridge 2009), has not been closely examined. Results of experiments involving girdling of the basal branches showed 
their suppressive influence acts via at least two different mechanisms. Firstly, they support the earlier postulate that these branches act via export of an inhibitory influence (Dun et al. 2009); and, secondly, for the first time, demonstrate their role as competitive sinks for a rootderived stimulus to axillary bud outgrowth, particularly in the presence of the main stem apical bud.

\section{Bud outgrowth suppression by basal branches}

\section{Export of an inhibitory signal}

Girdling treatments supported the hypothesis that basal branches export a signal via their symplast that is inhibitory to axillary bud outgrowth. As with Trifolium repens (Thomas et al. $2003 a$ ), it is the buds on the basal branches that lead to their inhibitory influence. On the basis of experiments with Arabidopsis (Ongaro and Leyser 2008; Ongaro et al. 2008)) and Medicago truncatula (C. Mouchel and O. Leyser pers. comm.) it has been suggested that this inhibitory influence might be exerted via the export of auxin from these actively growing branches into the main stem. This could then lower the sink strength for auxin in the PATS system within the main stem such that auxin export from distally located buds is prevented, thereby inhibiting their outgrowth (the canalization hypothesis (Ongaro et al. 2008; Leyser 2009)). Neither the present results with $P$. sativum, nor those obtained previously for $T$. repens (Thomas and Hay 2011, 2015b) support this hypothesis, however. In each case replacement of excised basal branches by applied NAA failed to inhibit bud outgrowth. The nature of the exported inhibitor thus remains undetermined.

\section{Competitive sink activity}

Girdling of basal branches in P. sativum did not completely overcome their suppressive effect, particularly in the presence of the main stem apical bud (Figs. 1 and 2 group $A(+A B)$, (C) vs. (G) vs. (X)). Thus, in addition to possibly exporting an inhibitor, basal branches must also act by removing a necessary stimulant from the xylem in competition with distal regions of the main stem. A similar response has been reported previously in nodally rooting $T$. repens (Thomas and Hay 2011) in which strong evidence suggests that this putative stimulant is exported into the shoot system from roots. The additional observation that induced formation of adventitious roots on Petunia stems stimulates bud outgrowth (Janssen et al. 2010) supports the possibility that the xylem-transported promoter in P. sativum might also be root-derived. Although the nature of this stimulant has not been defined, possible involvement of cytokinins is suggested by the demonstration that the bud outgrowth response 
to nodal roots in $T$. repens can be simulated by the application of xylem-transported benzyladenine (Thomas and Hay 2015a). The action of basal branches as competitive sinks clearly warrants further investigation.

An alternative possibility that the action of basal branches as competitive sinks for sucrose might be the cause of reduced axillary bud outgrowth, seems unlikely. Sucrose is a known stimulant of axillary bud outgrowth in P. sativum (Mason et al. 2014). Disbudding of basal branches would decrease their sink activity while maintaining photosynthetic activity of their retained leaves, and, as a result, the availability of exportable sucrose to other shoot and root tissues would increase. Blocking the export of this sucrose via the symplast by application of a girdle (treatment $(\mathrm{D}+\mathrm{G})$, Fig. 1) does not prevent the stimulatory effect of disbudding, however.

\section{Bud outgrowth in response to decapitation}

The confinement of stimulated bud outgrowth in response to decapitation of otherwise intact plants to only a very few nodes immediately below the point of excision of apical tissues is commonly observed in a wide range of annual and perennial species (Cline 1991, 1997). These distalmost buds then grow out to form a few branches one of which replaces the original growing tip of the main stem. In the present study, as in the rms2.1 mutant of $c v$. Torsdag (Ferguson and Beveridge 2009), decapitation above node 12 in Experiments 1 and 2 stimulated outgrowth of the upper two buds only (Figs. 1 and 2, treatment $\mathrm{C} \pm \mathrm{AB}$ ). The suppression of bud outgrowth proximal to these rapidly growing replacement branches has often been interpreted as possibly the result of basipetal export of an inhibitory influence (auxin) from them (Hillman 1984). In P. sativum, however, this certainly cannot be the only cause because, in the absence of basal branches in the present study, outgrowth of all buds in the inhibition zone proximal to the replacement branches at nodes 11 and 12 was stimulated in decapitated plants (Figs. 1 and 2, Group B (-AB) treatments X vs. C). This finding is unique and is only revealed now as a result of procedures involving excision of basal branches, or excision of their active buds, in combination with decapitation. Outgrowth responses have been reported to treatments of basal branch excision, main stem girdling and decapitation (Ferguson and Beveridge 2009) but not to the combination of both basal branch excision and main stem decapitation.

Multiple regulatory pathways 
Observations on axillary bud outgrowth in P. sativum by Ferguson and Beveridge (2009) led them to conclude that "apical dominance (and) correlative inhibition (by basal branches) --are independent but interacting mechanisms for regulating bud outgrowth". This conclusion was based on their finding that the suppressive effect of basal branches is independent of the action of strigolactones. Although strigolactones play a major regulatory role in the control of apical dominance via its interactions with auxin and cytokinin (Hayward et al. 2009; Brewer et al. 2009, 2013; Crawford et al. 2010; Dun et al. 2012; Shinohara et al. 2013; Bennett et al. 2016), they found that the stimulatory effect of basal branch excision in a range of RAMOSUS strigolactone pathway mutants was no different from that in wild type. The present observation that the combined effect of decapitation and basal branch excision was additive (Figs. 1 and 2, treatment $(\mathrm{X})-\mathrm{AB}$ ) adds strength to that conclusion. The third regulatory mechanism, involving competition between the basal branches and the more distal regions of the shoot system for a finite pool of bud outgrowth promoter, adds to the complexity of the interacting regulatory systems.

The inhibitory effect of basal branches was not confined to suppression of outgrowth of quiescent axillary buds on the main stem; it also strongly delayed the time of their initiation within the main stem apical bud by two or three plastochrons (Fig. 6). This raises the question as to whether all stages of bud development are under the control of a common signal or whether, alternatively, the various stages are independently regulated. More particularly, is bud initiation, perhaps, more under the control of the availability of promoters rather than under the influence of inhibitors? Removal of competition for promoters by continual excision of axillary buds in Experiment 4 (Fig. 6) would have concomitantly maximised the supply of promoter to the main stem apical bud while eliminating the inhibitory influence of basal branches. In addition, removal of potential sinks for the pool of photoassimilates accumulated in the fully retained foliage could have led to enhanced vigour of the apical bud. Sucrose has been shown to be implicated in both the release of buds from their quiescent state and to stimulate their further outgrowth in P. sativum (Mason et al. 2014). Whether it also influences the plastochronal timing of bud initiation within the apical bud is not known.

\section{Variation in bud outgrowth potential}

Positional variation in bud outgrowth responses to decapitation is well documented for $P$. sativum plants in which basal branches and /or buds are present (Hussain and Linck 1966; King and van Staden 1988; Ferguson and Beveridge 2009). The present results show, 
however, that, in the absence of suppressive influences of basal branches and/or buds, all distal buds have similar intrinsic outgrowth potentials (Fig. 4 (ii) a vs. b vs. c). The observation that buds at node 12 were able to grow out in response to decapitation in the presence of vigorous basal branches whereas those lower on the main stem were not (Figs. 3 and 4) suggests that shortage of bud outgrowth stimulant was not limiting the response of lower buds. Instead, it strongly suggests the involvement of an inhibitory signal from the basal branches. The variation in outgrowth response of buds along the main stem must therefore result either from the acropetally decreasing availability of an inhibitor exported via the phloem of basal branches or from an acropetally decreasing sensitivity of the buds to such an inhibition. Available data do not allow the possibility of distinguishing between these alternative possibilities. Positional variation in sensitivity has been reported, though, in relation to bud outgrowth in response to application of cytokinins (King and van Staden 1988) and in the expression of cytokinin biosynthesis genes in response to stem decapitation and girdling at differing positions on the main stem (Ferguson and Beveridge 2009).

Such changes in sensitivity might well be related to the development of plants from a vegetative state (perhaps ending at approximately nodes 9 or 10) through to a reproductive phase (beginning at approximately node 11) that leads to enhanced branching in the enrichment zone (Weberling 1989). During the later stages of vegetative growth, the strong sensitivity of buds at nodes 6 to 9 in the inhibition zone to the suppressive influences of basal branches restricts their outgrowth in response to decapitation. This is lost in the buds at nodes 11 and 12, enabling them to grow out into replacement branches following decapitation of the main stem. The possible existence of a relationship between this change in sensitivity and the onset of the transition to the reproductive state is in keeping with the suggestion, based on evidence obtained by Ferguson et al. (1991), that the transition to the reproductive state at the SAM in P. sativum takes place approximately eight plastochrons before the formation of the first flower primordium. In the present study the latter occurred at approximately node 20 .

A similar confinement of bud outgrowth to the two or so distalmost remaining nodes in response to decapitation in T. repens and other prostrate nodally rooting herbs (Thomas and Hay 2004) is not explicable on the same basis, however. When these plants are grown in conditions that prevent flowering, the pattern of bud outgrowth in response to decapitation is similar regardless of the position of that decapitation relative to the basal branches. It should be noted though, as mentioned earlier, that the predominant mechanism by which basal branches suppress distal bud outgrowth in T. repens is via their action as competitive sinks 
for root-derived promoters (Thomas et al. 2003a, 2014; Thomas and Hay 2011), whereas in decapitated plants of $P$. sativum their export of an inhibitory signal is more strongly involved (Dun et al. 2009).

These findings highlight the importance of recognising the possible existence of variations in both bud sensitivity and in regulatory mechanisms for the interpretation of bud outgrowth responses to decapitation in future studies.

\section{Adaptive significance of bud outgrowth suppression by basal branches}

The possible adaptive significance of the suppressive role of basal branches is clear. Suppression of bud outgrowth in the inhibition zone of the main stem of orthotropic annuals has been speculated to convey at least two advantages (Müller and Leyser 2011). Firstly, it reduces competition with the apical bud for resources essential for growth, thereby maximising growth upwards in the canopy and consequently increasing the chances of pollination of flowers in the terminal inflorescence. Secondly, it provides for the establishment of a 'bud bank' making a pool of meristems available for regrowth should major damage to the aerial shoot system occur (Harper 1977). Should these speculations be correct, unrestricted outgrowth of buds at all nodes along the main stem would be disadvantageous. Basal branches play a major role in suppressing such outgrowth in intact plants of both $P$. sativum and prostrate, nodally-rooting, clonal herbs such as T. repens (Thomas and Hay 2004, 2008b, 2011). In the case of $P$. sativum, following the removal of the main stem's apical bud, all buds along the main stem are stimulated to grow out strongly in the absence of basal branches (Figs. 1 and 2 group B (-AB), (X) vs. (C)), potentially leading to the formation of a dense cluster of overcrowded competing branches. In the presence of basal branches, however, axillary bud outgrowth is confined to the uppermost few remaining nodes and overcrowding is avoided.

\section{Acknowledgements}

We thank Rachael Sheridan and Lily Ouyang for technical assistance and John Koolard for statistical assistance. We also thank Dr J. Bachelier and two anonymous referees for constructive comments that have improved the text. This work was supported in part by the MeriNet programme, New Zealand Foundation for Research, Science and Technology, grant numbers C10X0404 and C10X0816 and AgResearch Limited. 


\section{References}

Brewer, P.B., Dun, E.A., Ferguson, B.J., Rameau, C., and Beveridge, C.A. 2009.

Strigolactone acts downstream of auxin to regulate bud outgrowth in pea and Arabidopsis. Plant Physiol. 150: 482-493.

Brewer, P.B., Koltai, H., and Beveridge, C.A. 2013. Diverse roles of strigolactones in plant development. Mol. Plant, 6: 18-28.

Cline, M.J. 1991. Apical dominance. Bot. Rev. 57: 318-358.

Cline, M.J. 1997. Concepts and terminology of apical dominance. Am. J. Bot. 84: 1064-1069.

Crawford, S., Shinohara, N., Sieberer, T., Williamson, L., George, G., Hepworth, J., Müller, D., Domagalska, M.A., and Leyser, O. 2010. Strigolactones enhance competition between shoot branches by damping auxin transport. Dev. 137: 2905-2913.

Dun, E.A., Ferguson, B.J., and Beveridge, C.A. 2006 Apical dominance and shoot branching. Divergent opinions or divergent mechanisms. Plant Physiol. 142: 812-819.

Dun, E.A., Hanan, J., and Beveridge, C.A. 2009. Computational modelling and molecular physiology experiments reveal new insights into shoot branching in pea. Plant Cell, 21: 34593472 .

Dun, E.A., de Saint Germain, A., Rameau, C., and Beveridge, C.A. 2012. Antagonistic action of strigolactone and cytokinin in bud outgrowth control. Plant Physiol. 158: 487-498.

Ferguson, B.J., and Beveridge, C.A. 2009. Roles for auxin, cytokinin and strigolactone in regulating shoot branching. Plant Physiol. 149: 1929-1944.

Ferguson, C.J., Huber, S.C., Hong, P.H., and Singer, S.R. 1991. Determination for inflorescence development is a stable state, separable from determination for flower development in Pisum sativum L. buds. Planta, 185: 518-522.

Harper, J.L. 1977. The population biology of plants. Academic Press, London.

Hayward, A., Strirnberg, P., Beveridge, C., and Leyser, O. 2009. Interactions between auxin and strigolactone in shoot branching control. Plant Physiol. 151: 400-412.

Hillman, J.R., Math, V.B., and Medlow, G.C. 1977. Apical dominance and the levels of indole acetic acid in Phaseolus lateral buds. Planta, 134: 191-193.

Hussain, S.M., and Linck, A.J. 1966. Relationship of apical dominance to the nutrient accumulation pattern in Pisum sativum var. Alaska. Physiol. Plant. 19: 992-1010.

King, R.A., and van Staden, J. 1988. Differential responses of buds along the shoot of Pisum sativum to isopentenyladenine and zeatin application, Plant Physiol. Biochem. 26: 253-259. 
Leyser, O. 2009. The control of shoot branching: an example of plant information processing. Plant Cell Environ. 32: 694-703.

Mason, M.G., Ross, J.J., Babst, B.A., Wienclaw, B.N., and Beveridge, C.A. 2014. Sugar demand, not auxin, is the initial regulator of apical dominance. Proc. Natl. Acad. Sci. USA. 111: 6092-6097.

Müller, D., and Leyser, O. 2011. Auxin, cytokinin and the control of shoot branching. Ann. Bot. 107: 1203-1212.

Napoli, C.A., Beveridge, C.A., and Snowden, K.C. 1999. Reevaluating concepts of apical dominance and the control of axillary bud outgrowth. Dev. Biol. 44: 127-169.

Newton, P.C.D., Hay, M.J.M., Thomas, V.J., and Dick, H.B. 1992. Viability of axillary buds of white clover (Trifolium repens) in grazed pasture. J. Agric. Sci. Camb. 119: 345-354.

Ongaro, V., and Leyser, O. 2008. Hormonal control of shoot branching. J. Exp. Bot. 59: 6774.

Ongaro, V., Bainbridge, K., Williamson, L., and Leyser, O. 2008. Interactions among axillary branches of Arabidopsis. Mol. Plant, 1: 388-400.

Phillips, I.D.J. 1975. Apical dominance. Ann. Rev. Plant Physiol. 26: 431-367.

Porter, C.L. 1959. Taxonomy of flowering plants. WH Freeman, San Francisco.

Rameau, C., Bertheloot, J., Leduc, N., Andrieu, B., Foucher, F., and Sakr, S. 2015. Multiple pathways regulate shoot branching. Front. Plant Sci. doi: 10.3389/fpls.2014.00741.

Shimizu-Sato, S., Tanaka, M., and Mori, H. 2009. Auxin-cytokinin interactions in the control of shoot branching. Plant Mol. Biol. 69: 429-435.

Shinohara, N., Taylor, C., and Leyser, O. 2013. Strigolactone can promote or inhibit shoot branching by triggering rapid depletion of the auxin afflux protein PIN1 from the plasma membrane. PLoS Biol. 11: e1001474.

Snow, R. 1931. Experiments on growth inhibition. Part 2: New phenomena of inhibition. Proc. Roy. Soc. 108: 305-316.

Stafstrom, J.P. 1995. Developmental potential of shoot buds. In Plant stems: Physiology and functional morphology. Edited by B.L. Gartner. Academic Press, San Diego, U.S.A. pp. 257279.

Tamas, I.A. 1995. Hormonal regulation of apical dominance. In Plant hormones, physiology, biochemistry and molecular biology. Edited by P.J. Davies. Kluwer Academic Publishers, Dordrecht, Germany. pp. 572-597.

Tanaka, M., Takei, K., Kojima, M., Sakakibara, H., and Mori, H. 2006. Auxin controls local cytokinin biosynthesis in the nodal stem in apical dominance. Plant J. 45: 1028-1036.

Thomas, R.G., and Hay, M.J.M. 2004. Evidence suggests plagiotropic clonal species have evolved a branching physiology emphasizing regulation by nodal roots. Evol. Ecol. 18: 409428. 
Thomas, R.G., and Hay, M.J.M. 2008a. White clover and garden pea have contrasting branching behaviour but share common regulatory mechanisms. Fourth International Conference on Legume Genomics and Genetics, Puerto Vallarta, Mexico, Conference Handbook, p. 75.

Thomas, R.G., and Hay, M.J.M. 2008b. Adaptive variation in physiological traits underpinning stem elongation responses among nodally-rooting herbs. Evol. Ecol. 22: 369381.

Thomas, R.G., and Hay, M.J.M. 2011. Existing branches correlatively inhibit further branching in Trifolium repens: possible mechanisms. J. Exp. Bot. 62: 1027-1036.

Thomas, R.G., and Hay, M.J.M. 2014. Shoot branching in nutrient-limited Trifolium repens is primarily restricted by shortage of root-derived promoter signals. Funct. Plant Biol. 41: 401-410.

Thomas, R.G., and Hay, M.J.M. 2015a. Shoot branching in response to nodal roots is mimicked by application of exogenous cytokinin in Trifolium repens L. Funct. Plant Biol. 42: $115-125$.

Thomas, R.G., and Hay, M.J.M. 2015b. Regulation of correlative inhibition of axillary bud outgrowth by basal branches varies with growth stage in Trifolium repens. J. Exp. Bot. 66: 3803-3813.

Thomas, R.G., Hay, M.J.M., and Newton, P.C.D. 2002. A developmentally based categorisation of branching in Trifolium repens L.: Influence of nodal roots. Ann. Bot. 90: 379-389.

Thomas, R.G., Hay, M.J.M., and Newton, P.C.D. $2003 a$. Relationships among shoot sinks for resources exported from nodal roots regulate branch development of distal non-rooted portions of Trifolium repens L. J. Exp. Bot. 54: 2091-2104.

Thomas, R.G., Hay, M.J.M., Newton, P.C.D., and Tilbrook, J.C. 2003b. Relative importance of nodal roots and apical buds in the control of branching in Trifolium repens L. Plant Soil, 255: 55-66.

Thomas, R.G., Li, F.Y., and Hay, M.J.M. 2014. Differential bud activation by a net positive signal explains branching phenotype in prostrate clonal herbs: a model. J. Exp. Bot. 65: 673682.

VSN International. 2015. GenStat for Windows. 18th Edition. VSN International, Hemel Hempstead, UK

Weberling, F. 1989. Morphology of Flowers and Inflorescences. Cambridge University Press, Cambridge, UK. 
Table 1. Mean sum of the increases in length of axillary buds at nodes 13,14 and 15 in response to treatments in Experiment 2

Plants remained intact (untreated (C) or with NPA applied to two basal branches (NPA)); or were debranched at the two basal nodes (with (NAA) or without (X) NAA applied to remaining branch stubs); or had their two basal branches girdled $(\mathrm{G})$; or were totally debranched and disbudded up to node 12 (Z). Data for days 0-4 show increases in overall bud lengths, and those for days 5-9 show increases in bud stem lengths $(\mathrm{mm}), n=6$. Data were $\log$ transformed for ANOVA analysis and the LSD 5\%, (d.f. $=25)$ is presented for treatment comparison

\begin{tabular}{|c|c|c|c|c|c|c|c|}
\hline \multirow{3}{*}{$\begin{array}{l}\text { Time } \\
\text { Period }\end{array}$} & \multicolumn{6}{|c|}{ TREATMENTS } & \multirow[b]{3}{*}{ LSD } \\
\hline & \multicolumn{2}{|c|}{ Intact } & \multicolumn{2}{|c|}{$\begin{array}{l}\text { Nodes } 1 \& 2 \\
\text { debranched }\end{array}$} & \multirow{2}{*}{$\begin{array}{c}\begin{array}{c}\text { Intact + } \\
\text { girdle }\end{array} \\
\text { (G) }\end{array}$} & \multirow{2}{*}{$\begin{array}{c}\text { Nodes 1-11 } \\
\text { disbudded } \\
\text { (Z) }\end{array}$} & \\
\hline & (C) & (NPA) & $(X)$ & (NAA) & & & \\
\hline \multicolumn{8}{|l|}{$0-4 d$} \\
\hline & 5.3 & 5.4 & 10.8 & 9.5 & 7.7 & 11.2 & \\
\hline (log means) & 1.53 & 1.65 & 2.28 & 2.17 & 1.95 & 2.37 & 0.34 \\
\hline \multicolumn{8}{|l|}{$5-9 d$} \\
\hline & 0.2 & 0.3 & 10.5 & 7.1 & 0.3 & 26.5 & \\
\hline (log means) & 0.12 & 0.18 & 1.78 & 2.05 & 0.23 & 2.81 & 1.02 \\
\hline
\end{tabular}


Table 2. Effect of applied NAA and NPA on increases in axillary bud lengths (mm) from day 0 to day 2 at nodes 3, 4 and 5 in plants in Experiment 2

Plants either remained intact with or without application of NPA to basal branches ((NPA) or (C) respectively); or had their two basal branches excised (debranched) with or without NAA applied to the remaining branch stubs ((NAA or (X) respectively); or had their two basal branches girdled $(G)$. Main stems retained their apical buds $(+A B)$ or were decapitated $(-A B)$, $n=6$. Standard errors are shown in parentheses

\begin{tabular}{|c|c|c|c|c|c|c|c|}
\hline \multirow{2}{*}{\multicolumn{2}{|c|}{ TREATMENT }} & \multicolumn{2}{|c|}{ Node 3} & \multicolumn{2}{|c|}{ Node 4} & \multicolumn{2}{|c|}{ Node 5} \\
\hline & & $+A B$ & $-A B$ & $+A B$ & $-A B$ & $+A B$ & $-A B$ \\
\hline \multirow[t]{2}{*}{ Intact: } & -NPA (C) & $\begin{array}{c}0.3 \\
(0.20)\end{array}$ & $\begin{array}{c}0.7 \\
(0.25)\end{array}$ & $\begin{array}{c}0.5 \\
(0.34)\end{array}$ & $\begin{array}{c}0.5 \\
(0.18)\end{array}$ & $\begin{array}{c}0.1 \\
(0.08)\end{array}$ & $\begin{array}{c}0.1 \\
(0.08)\end{array}$ \\
\hline & +NPA (NPA) & $\begin{array}{l}0.0 \\
(0)\end{array}$ & $\begin{array}{c}0.3 \\
(0.17)\end{array}$ & $\begin{array}{c}0.4 \\
(0.20)\end{array}$ & $\begin{array}{c}0.5 \\
(0.26)\end{array}$ & $\begin{array}{c}0.2 \\
(0.17)\end{array}$ & $\begin{array}{c}0.3 \\
(0.17)\end{array}$ \\
\hline \multirow[t]{2}{*}{ Debranched: } & -NAA (X) & $\begin{array}{c}2.4 \\
(0.89)\end{array}$ & $\begin{array}{c}4.8 \\
(1.56)\end{array}$ & $\begin{array}{c}1.0 \\
(0.21)\end{array}$ & $\begin{array}{c}2.8 \\
(0.28)\end{array}$ & $\begin{array}{c}1.0 \\
(0.29)\end{array}$ & $\begin{array}{c}1.8 \\
(0.25)\end{array}$ \\
\hline & +NAA (NAA) & $\begin{array}{c}2.0 \\
(0.53)\end{array}$ & $\begin{array}{c}3.8 \\
(0.89)\end{array}$ & $\begin{array}{c}0.8 \\
(0.33)\end{array}$ & $\begin{array}{c}2.2 \\
(0.17)\end{array}$ & $\begin{array}{c}0.7 \\
(0.38)\end{array}$ & $\begin{array}{c}2.3 \\
(0.28)\end{array}$ \\
\hline Girdled: & (G) & $\begin{array}{c}4.4 \\
(1.86)\end{array}$ & $\begin{array}{c}3.0 \\
(0.43)\end{array}$ & $\begin{array}{c}0.5 \\
(0.22)\end{array}$ & $\begin{array}{c}2.2 \\
(0.28)\end{array}$ & $\begin{array}{c}1.2 \\
(0.21)\end{array}$ & $\begin{array}{c}2.0 \\
(0.27)\end{array}$ \\
\hline
\end{tabular}




\section{Figure Captions}

Figure 1. The effect of treatment to the two basalmost branches (at nodes 1 and 2) on the outgrowth of axillary buds present at each node distal to them on the main stem in Experiment 1. At the time of treatments, node 12 was the youngest that had emerged from its parent apical bud. This apical bud $(\mathbf{\Lambda})$ remained attached in group $A(+A B)$ but was excised distal to node $12(=)$ in all plants in group B $(-\mathrm{AB})$. Nodes that emerged from the main stem apical bud after treatments were imposed are shown above the horizontal broken line in group A. In both groups, as indicated by the symbols at nodes 1 and 2, the two basalmost branches remained untreated in $(\mathrm{C}, \rightarrow)$, were totally excised in treatment $(X,-11)$, girdled near their bases in $(\mathrm{G},-\square \rightarrow)$, disbudded in $(\mathrm{D},-\mathrm{X})$ and both disbudded and girdled in $(\mathrm{D}+\mathrm{G},-\square-\mathrm{X}), n=$ 8. The y-axes represent the plant's main stems. For each node in each treatment in Groups A and $B$ the white horizontal bars show the increase in overall lengths of buds from days 0 to 4 and the black bars show the subsequent increase in bud stem lengths from days 5 to 9 . The different scales for these parameters are shown below the x-axes. Error bars indicate the standard errors of means.

Figure 2. The effect of treatment to the basalmost branches (at nodes 1 and 2) on the outgrowth of buds at each node distal to them on the main stem in Experiment 2. At the time of treatment, node 12 was the youngest emerged from the main stem apical bud. This apical bud $(\Theta)$ remained attached $(+\mathrm{AB})$ in group $\mathrm{A}$, but was excised distal to node $12(=)$ from all plants in group B (-AB). Nodes emerging after treatments were imposed are shown above the horizontal broken line in the former group. In both groups the basalmost branches at nodes 1 and 2 were untreated in $(\mathrm{C}, \rightarrow$ ), received NPA on their basal internodes in (NPA $-0 \longrightarrow$ ), and were girdled near their bases in treatment $(\mathrm{G},-\square \rightarrow)$. In treatments $(X,-11)$ and (NAA, $-\| \mathrm{D})$ the two basalmost branches were excised and NAA applied to their remaining stubs in the latter, $(n=6)$. The y-axes represent the plants' main stems. For each node in each treatment in Groups A and B, the white horizontal bars show the increase in overall lengths of buds from days 0 to 4 and the black bars show the subsequent increase in bud stem lengths from days 5 to 9. Scales on the x-axes are the same for both Group A and B and the same for both parameters. Error bars indicate the standard errors of means.

Figure 3. Bud outgrowth in response to decapitation of the main stem, showing the increase in bud lengths after $7 \mathrm{~d}$ in Experiment 3. Treatments were applied when node 12 was newly emerged from the apical bud on the main stem; plants then either retaining their apical buds (i) or were decapitated above node 12 (ii) or 9 (iii). All buds and branches at nodes 1 to 4 (not 
shown) were retained in all treatments, $n=6$. Error bars indicate the standard errors of the means.

Figure 4. Bud outgrowth after $7 \mathrm{~d}$ in response to decapitation and to excision of proximal buds and branches from nodes along the main stem in Experiment 4. Apical buds were excised from the main stem when nodes 12 (group a), 9 (group b) or 5 (group c) were newly emerged from them. Within each group, all axillary buds along the main stem, and branches developed from them, were retained in treatment (i) (but not shown at nodes 1-4 for groups a and b). In treatments (ii) and (iii), two distal buds were retained at nodes 11 and 12, 8 and 9 and 4 and 5 in groups $\mathbf{a}, \mathbf{b}$ and $\mathbf{c}$ respectively, but all others proximal to them were excised, either at the time the plants were decapitated (X, treatment (ii) late disbudding) or immediately each of the nodes bearing them emerged from the main stem apical bud (I, treatment (iii) continual disbudding), $n=6$. Error bars indicate the standard error of means.

Figure 5. The impact of the treatments to basal branches on the relationship between the initial length of the axillary bud at node 3 and that attained by it after $4 \mathrm{~d}$ for non-decapitated plants in Experiment 2. Regression lines were fitted for each treatment $(n=6): C=$ intact untreated control plants, $y=-0.38+1.21 x ; \mathrm{NPA}=$ plants with the two basalmost branches NPA treated, $y=0.17+1.02 x ; G=$ plants with the two basalmost branches girdled, $y=0.61$ $+2.49 \mathrm{x} ; \mathrm{X}=$ plants with the two basalmost branches excised, $\mathrm{y}=2.96+1.24 \mathrm{x} ; \mathrm{NAA}=$ plants with the two basalmost branches excised + NAA treated, $y=1.67+2.54 x$.

Figure 6. Lengths of axillary buds (L) present at the youngest two nodes emerged from the apical bud on the main stem in plants of three ages (at nodes 11 and 12 in (a), 8 and 9 in (b) and 4 and 5 in (c)) at the time the main stems were decapitated in Experiment 4; and the number of leaf primordia $(\mathrm{N})$ present in axillary buds at each node within the main stem apical bud proximal to these at that time. Axillary buds at main stem nodes proximal to nodes 11,8 and 4 in (a), (b) and (c) had either been excised continually up to the time of measurements (cont. disbud) or they were all retained up to this point (late disbud). F indicates the presence of a flower bud at a node and $\mathrm{Y}$ indicates the nodal position of the youngest leaf primordium within the main stem apical bud, $n=6$. Error bars indicate the standard error of means. 
Group A (+AB)
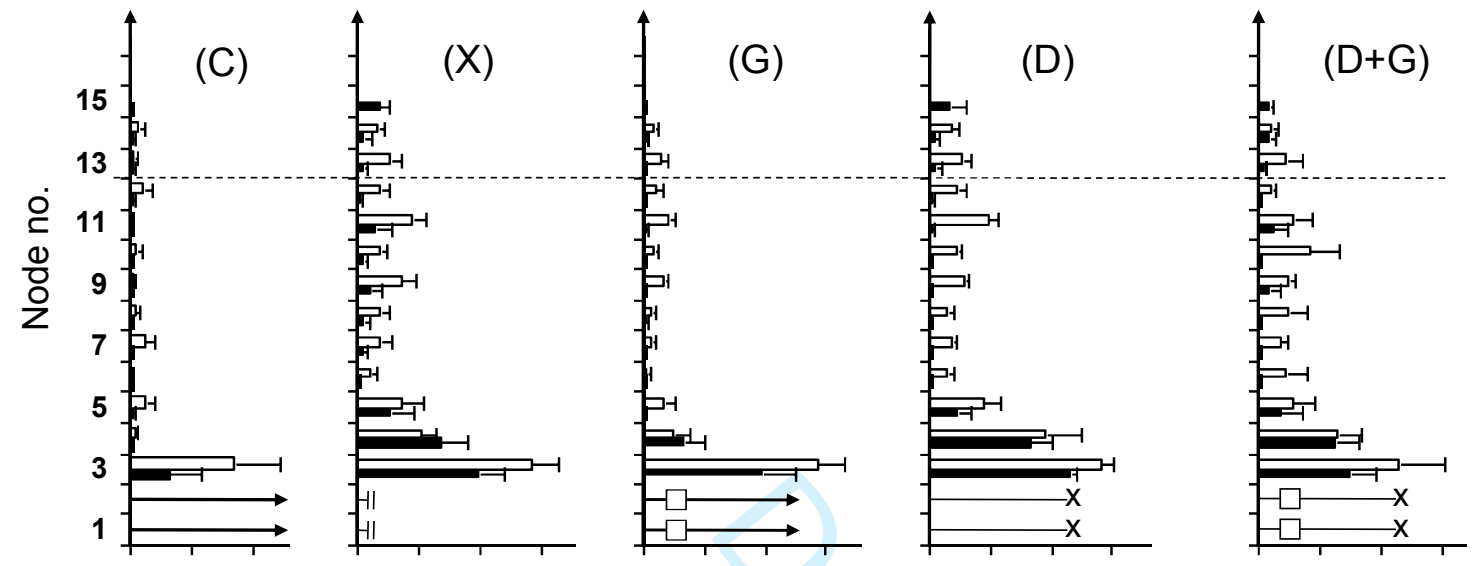

Group B (-AB)
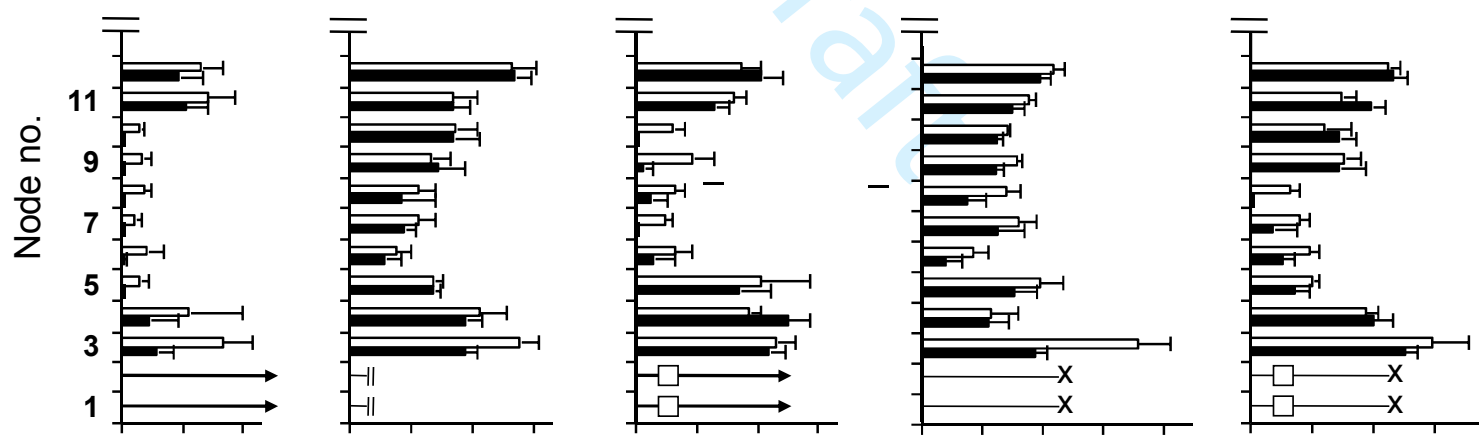

Bud length increase day 1 - day $4(\mathrm{~mm})$

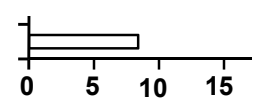

Bud stem length increase day 5 - day $9(\mathrm{~mm})$

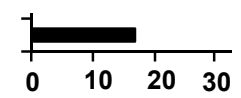

Fig. 1 

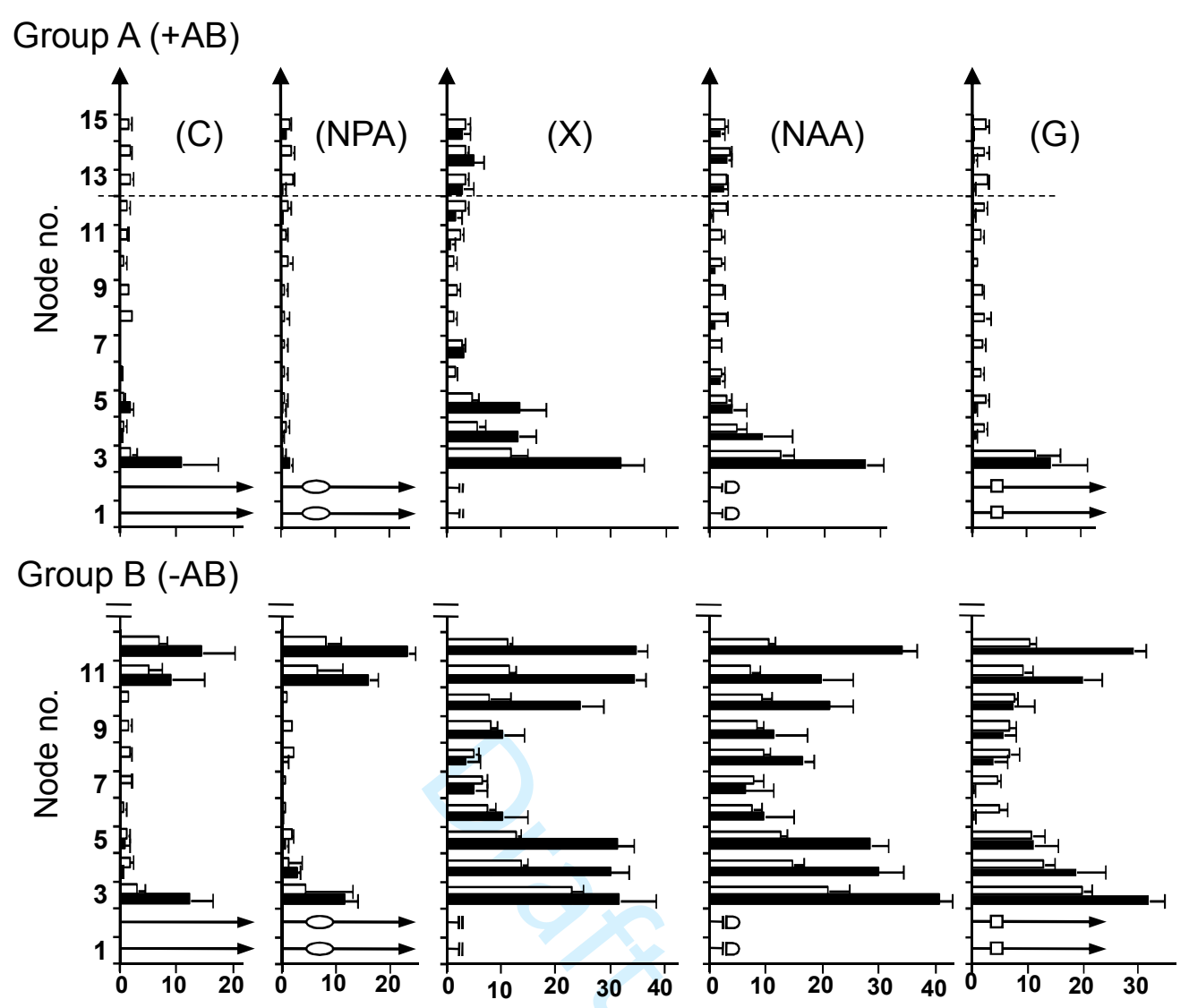

Bud length increase $(\mathrm{mm})$

Fig. 2 
<smiles>[C]1C=[As]C1</smiles> 


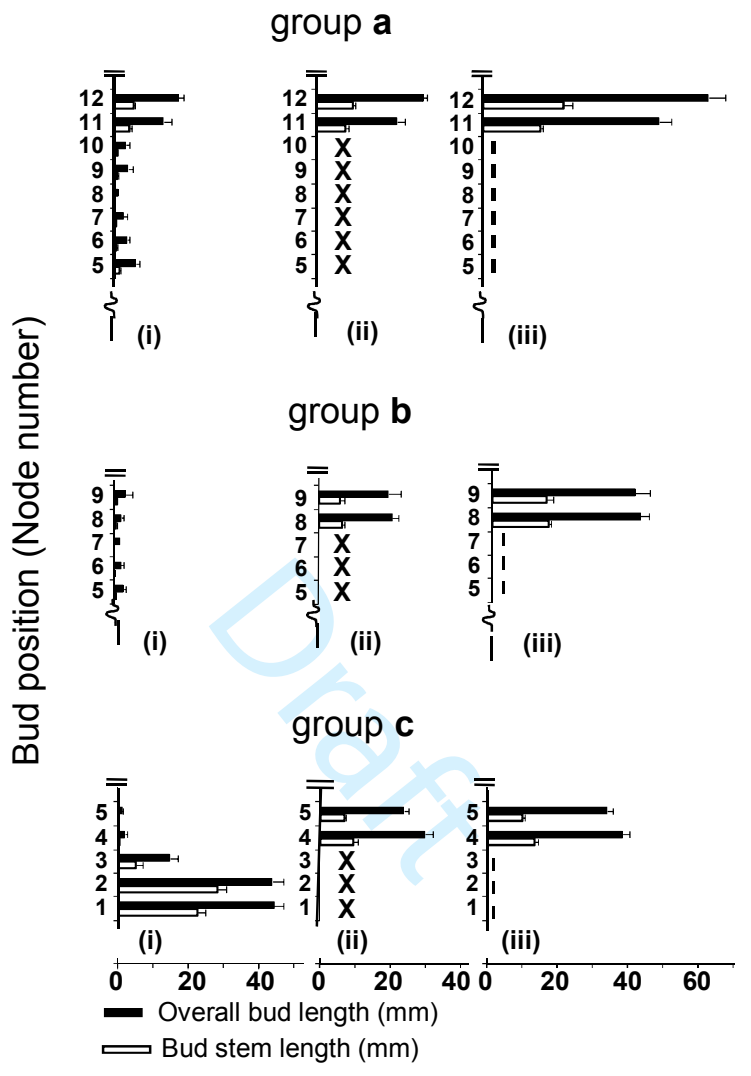

Fig. 4 


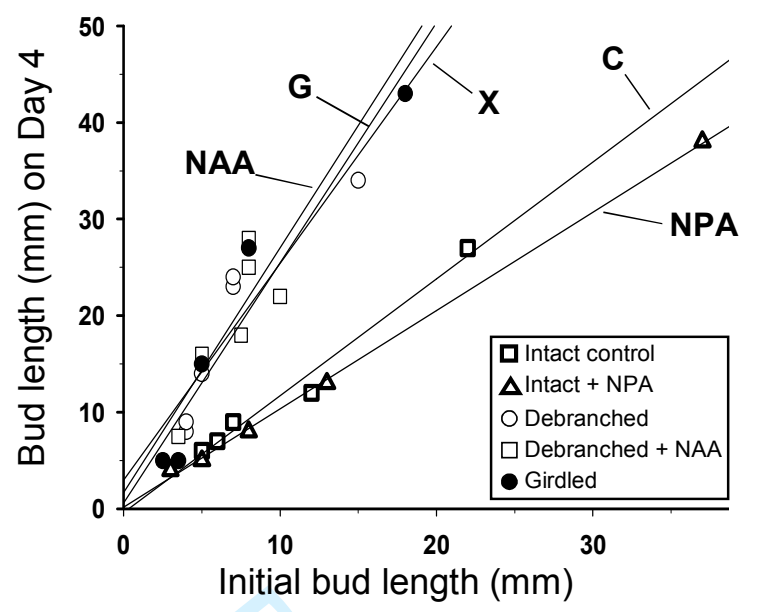

Fig. 5 
Botany

Page 32 of 32

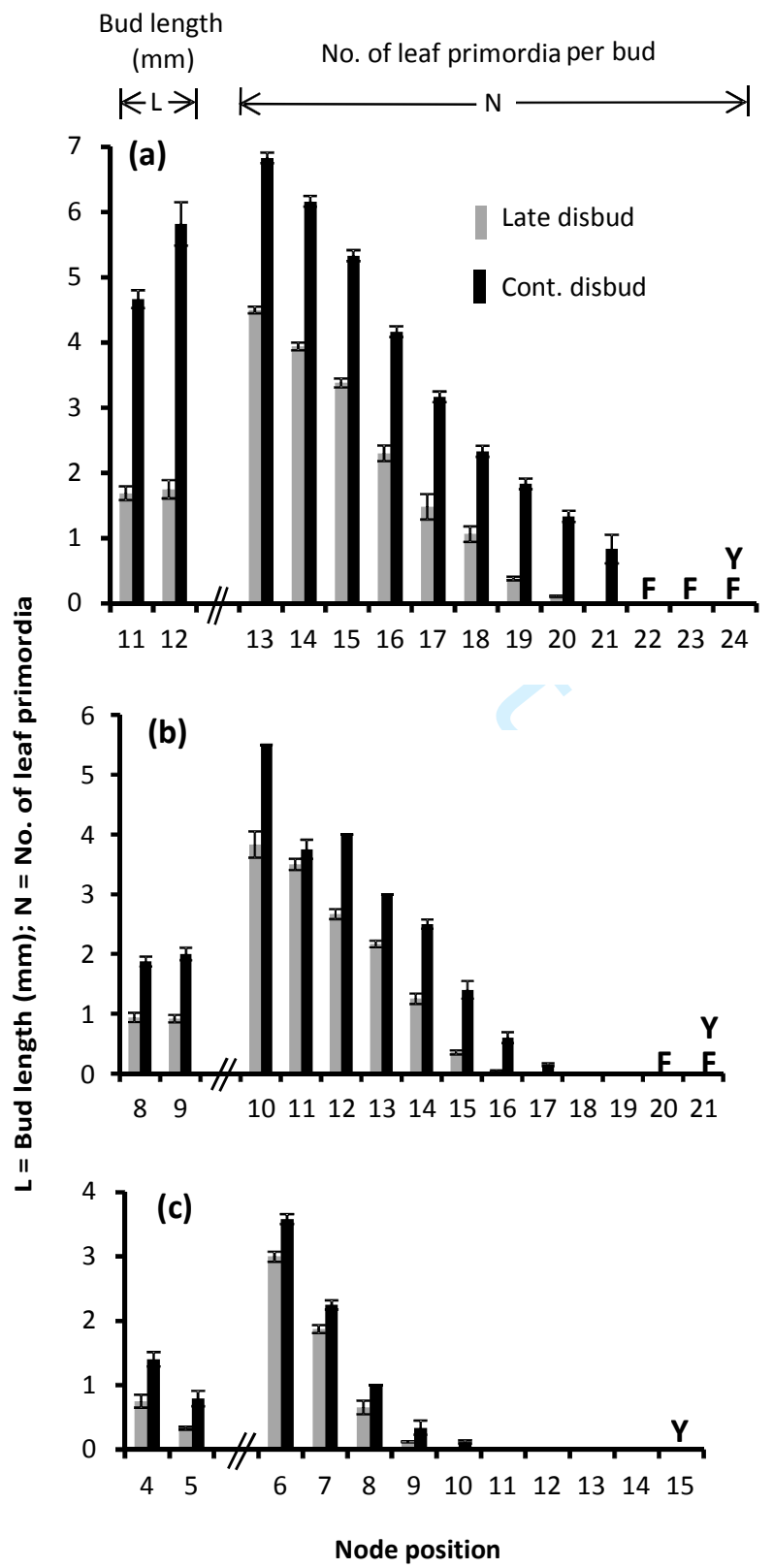

Fig. 6

https://mc06.manuscriptcentral.com/botany-pubs 